\title{
“EXPERIENCIAS Y REFLEXIONES DEL PROCESO ELECTORAL 2014-2015. LA IMPLEMENTACIÓN EN PERSPECTIVA DE LA REFORMA POLÍTICO- ELECTORAL". ENTREVISTA A LORENZO CÓRDOVA, CONSTANCIO CARRASCO Y SANTIAGO NIETO
}

César Astudillo: La reforma de 2012 fue vista como reforma del Estado y reforma electoral, por lo que es necesario apreciarla de una manera integral, porque sabemos que la legalidad y legitimidad de los procesos tienen un impacto muy importante sobre el funcionamiento de las instituciones del Estado mexicano. En este sentido, nos parece que esta visión dual de reforma del Estado y reforma electoral es una visión que se nutre por el conocimiento - que en una se produce y que inexorablemente se refleja en la otra一.

Las instituciones electorales, como el INE y la FEPADE, expresan un balance inicial del proceso de implementación de las leyes generales que le dan cobertura jurídica a su actuación, a sabiendas de que en 2014 se expidieron sendas leyes de instituciones y procedimientos electorales y de partidos políticos, así como de delitos electorales que pasaron por un proceso inicial de implementación; parte de éste todavía está inacabado y se encuentra en proceso de perfeccionamiento.

Una tercera institución, el Tribunal Electoral, funciona en materia de medios de impugnación con una ley de 1996, que fue diseñada en otro momento, en otro contexto, en otra realidad de nuestro país, por lo que valdría la pena reflexionar sobre cómo funciona esa ley a la luz de criterios jurisprudenciales y si ha evolucionado, y determinar cuáles serían los ajustes para actualizarla.

En ese sentido, les pregunto a Lorenzo Córdova, consejero presidente del Instituto Nacional Electoral; Constancio Carrasco Daza, presidente de la Sala Superior del Tribunal Electoral del Poder Judicial de la Federación, y Santiago Nieto Castigo, titular de la Fiscalía Especializada para la Atención de Delitos Electorales, ¿cuál es su opinión sobre la 
Esta obra forma parte del acervo de la Biblioteca Jurídica Virtual del Instituto de Investigaciones Jurídicas de la UNAM

reforma electoral 2014 en relación con su proceso de implementación?

Lorenzo Córdova: Si hacemos un primer balance, un corte de caja sobre la reforma 2014, en muchos sentidos continúa con una evolución que venía gestándose con reformas previas en algunos temas, como la fiscalización, dando sin duda un paso adelante en términos de robustecimiento a las atribuciones y los modos en los que se fiscaliza la política en nuestro país.

También es cierto que se trata de una reforma que a diferencia de las que le antecedieron, significa una refundación del sistema electoral en México. En las reformas previas, desde principios de los años noventa, figuraba un modelo electoral centrado en la coexistencia de 33 sistemas electorales, uno en cada entidad federativa y uno a nivel federal. Si bien éstos contaban con características comunes, nexos y canales de comunicación prácticamente en todo el país, tenían márgenes de diseño instrumentación distintas entre sí (salvo Baja California, sobre el uso del padrón electoral que el IFE generaba para efectos de las elecciones locales, o a partir de 2007 se concentraba en el IFE la administración de los tiempos del Estado, tanto para las elecciones locales como federales).

La reforma de 2014 es una reforma refundacional, pues constituye un único sistema electoral de carácter nacional en donde el INE ha jugado como una suerte de coordinador, de generador de directrices y de criterios comunes que buscan homogenizar y estandarizar la calidad de las elecciones y los procedimientos electorales a lo largo y ancho del país, tanto en las elecciones locales como en las elecciones federales.

Hoy a casi un año y medio de la aprobación de la reforma legal, el sistema electoral se transforma; ha pasado su primera prueba de ácido, es decir, su instrumentación en las elecciones concurrentes del 7 de junio pasado y las de Chiapas un mes después, lo que sin duda demuestra su viabilidad y su instrumentabilidad, luego de una polémica muy intensa en la que en algunos momentos tuvo participación el Senado, y donde se criticó la reforma y la impractibilidad del modelo nacional electoral.

Hoy podemos decir que es un modelo funcional, que en términos generales ha cubierto algunos de los propósitos iniciales, que sigue evolucionando porque es un modelo que ha sido muy complejo, que ha adquirido una importante generación no solamente de normas reglamentarias a cargo del INE, sino también de criterios a cargo 
Esta obra forma parte del acervo de la Biblioteca Jurídica Virtual del Instituto de Investigaciones Jurídicas de la UNAM

del propio INE y del Tribunal Electoral, pero que en términos generales han implicado un modelaje que demuestra su viabilidad y se encamina hacia un robustecimiento cada vez mayor.

El próximo año, de nuevo tendremos una prueba en términos de novedades de la misma reforma, por primera vez en la historia el INE está involucrado en la organización no ya de elecciones concurrentes sino de 13 elecciones locales. El INE ha decidido, por unanimidad de sus consejeros con derecho a voto, ejercer a plenitud las atribuciones que la reforma le confiere en términos de su presencia en lo local, lo que implica un impacto en muchos sentidos, entre ellos el presupuestal.

La parte más cara del proceso electoral le corresponde desarrollarla al INE, se trata del trabajo de campo, la capacitación, la insaculación y designación de los funcionarios de casilla, así como todo lo que tiene que ver con la designación o determinación de la ubicación de las casillas y de quienes las integran. Es decir, la reforma sigue a prueba, pero podemos hacer un corte de caja que en términos generales nos permite concluir que fue exitosa, ello a pesar de que su prueba de fuego se dio en un contexto sumamente complejo, en muchos sentidos inédito, por la complejidad social y política del país.

Las elecciones pasadas tuvieron que realizarse a pesar de un contexto poco propicio, incluso de planteamientos francos y abiertos que amenazaron con impedir el proceso electoral; sin embargo, hoy podemos decir que las elecciones se reivindicaron, entre otras cosas, gracias a la practicabilidad de la reforma como la vía privilegiada para recrear el intenso pluralismo político que nos caracteriza y al procesamiento de la competitividad política a través de la vía institucional; es decir, de vías pacíficas, de las vías planteadas en la reforma.

Sin embargo, hoy tenemos mucha claridad en los temas que valdría la pena repensar, en el entendido, como dicen los alemanes, que las reformas electorales son reformas interminables. Desde mi perspectiva, hoy no se necesita una refirma que refute el sistema electoral, pero siempre será pertinente una modificación a la normatividad, a la legislación, cuyos ajustes nos permitan tener un empaque legislativo lo más afinado posible para los desafíos que enfrentarán las autoridades electorales en la instrumentación de las reglas del juego democrático de cara a los futuros procesos electorales. 
Esta obra forma parte del acervo de la Biblioteca Jurídica Virtual del Instituto de Investigaciones Jurídicas de la UNAM

Desde la perspectiva del INE, me atrevería a señalar algunos puntos que valen la pena repensar y ajustar en clave legislativa, insisto en este código de no refundar el sistema electoral, de asumir que la reforma se ha demostrado practicable y ha servido para encausar en momentos sumamente complejos la conflictividad política y social del país por la ruta electoral. Sin embargo, pensando en prospectiva valdría la pena retomar o discutir, en primer lugar, uno de los temas que ha generado dolores de cabeza a las autoridades electorales, y lo digo con profundo respeto al Congreso, por la inactividad, por el trabajo no completado, como las reformas o las modificaciones legales que todavía están pendientes.

Desde la reforma de 2007 se introdujo una serie de prohibiciones en el artículo 134 que tienen que ver con la imparcialidad del uso de recursos por parte de servidores públicos; como con la prohibición de propaganda gubernamental personalizada se hablaba de la necesidad de la ley reglamentaria del 134, la cual no se procesó en la reforma de 2007, tan es así que hubo un reconocimiento de esa necesidad en la reforma de 2014, donde los transitorios establecieron que el Congreso de la Unión tendría que expedir dentro de un año, a partir de la reforma constitucional, la ley reglamentaria del artículo 134.

Desafortunadamente, esa ley todavía no se ha procesado y considero es indispensable para eliminar la instrumentación del tema por la vía de los criterios administrativos y jurisdiccionales del Tribunal Electoral. Cada vez que el Consejo General del INE conoce la eventual violación de un servidor público de estos preceptos constitucionales, son literalmente un dolor de cabeza abierto a la polémica, ya que no hay una reglamentación, no hay reglas del juego claramente establecidas de una legislación secundaria.

En segundo lugar, coincidiendo con César Astudillo, la reforma de 2014 cambia radicalmente el esquema de cómo se encausan los procedimientos especiales sancionadores, un procedimiento encaminado a resolver los asuntos de radio y televisión, pero también los asuntos que tienen que ver con eventuales o presuntos ilícitos que impactan el desarrollo de la contienda electoral.

La reforma de 2014 cambia la atribución exclusiva del IFE a una atribución compartida entre el INE y el Tribunal Electoral. Por un lado, el INE sustancia estos procedimientos y es la instancia ante la que se presentan las quejas, pero una vez sustanciados los procedimientos se turnan a la Sala Especializada del Tribunal, en tanto que la Sala 
Esta obra forma parte del acervo de la Biblioteca Jurídica Virtual del Instituto de Investigaciones Jurídicas de la UNAM

Superior es la garante última de la legalidad y constitucionalidad de las resoluciones que la Sala Especializada tome.

En la reforma hubo un cambio que, según consideramos, no debe estar en la égida del INE, se refiere a la resolución de las medidas cautelares, y no lo digo por la enorme carga política o exigencia política al momento de resolver las medidas cautelares, sino porque hay una inconsistencia: el INE es el órgano encargado de sustanciar y además emite la resolución de medidas cautelares y no es el mismo órgano que resuelve el fondo, rompiendo con esto la lógica omisiva de los procesos. Por ejemplo, en el juicio de amparo el mismo juez de la causa resuelve el fondo y determina la emisión o poder de la suspensión, que sería lo equivalente en el amparo en las medidas cautelares, por lo que creo que sería pertinente que la Sala Especializada se hiciera cargo en el futuro de las medidas cautelares y dejara al INE solamente la sustanciación, para darle racionalidad a este procedimiento.

En la reforma se hace mención que se crea la Sala Especializa para despresurizar políticamente al órgano electoral administrativo, en el entendido que es una institución que tiene que generar muchas actuaciones para inyectar confianza en el propio proceso electoral, y si se le deja resolver las quejas, se le inyecta un carácter dilutivo. Considero, pues, que la reforma de 2014 se quedó a medias.

Estimo que en una eventual reforma son indispensables cinco elementos:

\section{La legislación secundaria del artículo 134.}

\section{Las medidas cautelares del procedimiento especial sancionador.}

\section{La necesidad de regular de mejor manera las candidaturas independientes} desde la ley. Llegaron para quedarse, demostraron en la última elección que son viables para los ciudadanos en el acceso al poder político; sin embargo, son una serie de normas que están pendientes, como el financiamiento a las candidaturas, porque hay un dilema, la Constitución plantea la preeminencia del financiamiento público, pero si el financiamiento público con las reglas actuales prevalece podríamos volver en los hechos inviable una candidatura independiente. Queda como un tema abierto sin plantear soluciones sólo la necesidad de reflexionar al respecto. Otro tema sería hasta dónde vamos a llevar las exigencias para poder registrar una candidatura, porque si las exigencias son muy laxas las candidaturas independientes pueden desvirtuarse, y si las exigencias son muy altas, podrían volverse materialmente 
Esta obra forma parte del acervo de la Biblioteca Jurídica Virtual del Instituto de Investigaciones Jurídicas de la UNAM

impracticables. Ni una cosa ni la otra son pertinentes.

4. La modificación de los tiempos para concluir con la fiscalización. En este sentido hay un sano debate jurisdiccional con el Tribunal Electoral en el que la ley obliga al INE a resolver estos dictámenes dentro de los 45 días posteriores a la jornada electoral y con el criterio de la autoridad jurisdiccional, el cual está acatándose a plenitud; las quejas que atiende el INE, por una gestión de las cargas de trabajo que se desvinculan de los dictámenes, tienen que resolverse antes, ya que en 45 días tendría que solucionar quejas que no necesariamente se reflejan antes de la jornada electoral, y además los dictámenes, lo que vuelve prácticamente y desde el punto de vista material, inviable el trabajo exhaustivo que el INE quiere hacer.

Hoy todavía diversas campañas fiscalizadas ni siquiera se han resuelto en su definitividad por parte del Tribunal Electoral, porque muchos candidatos que ganaron tomarán posesión hasta enero, por lo que hay un tema legal que debe resolverse en cuanto a plazos, para permitir que los dictámenes de fiscalización de las campañas tengan un margen mayor al que se ha planteado en la legislación y con ello, la posibilidad de desahogar las quejas antes de que estos dictámenes se resuelvan.

Se trata de una cuestión de tiempos que puede afectar la intensidad y la exhaustividad con la que el INE está queriendo hacer la fiscalización. La flexibilización de los tiempos del modelo de comunicación política se ha demostrado practicable y creo que es pertinente por la apuesta que se ha hecho al uso de los tiempos del Estado y la prohibición de compra de publicidad. Pero también considero que resulta muy poco racional, ya que los spots de 30 segundos generan una saturación en la audiencia que no le conviene ni a las contiendas electorales ni a los propios partidos políticos, por no decir que la exposición de propuestas, proyectos, programas ideológicos es prácticamente imposible, y esto acaba generando un estímulo para que las contiendas electorales sean más contiendas de contraste y de confrontación.

Creo en un uso de los tiempos del Estado más racional y pertinente; como lo señala Raúl Trejo Delarbre: conviene una concentración de tiempo que estimule más el debate, programas de mayor aliento y que permita la exposición más intensa de la dimensión ideológica y programática de los partidos.

5. El financiamiento de los OPLES. El INE, en la práctica, tuvo la necesidad de dialogar con instancias locales para garantizar que se les financiaría su participación en el 
Esta obra forma parte del acervo de la Biblioteca Jurídica Virtual del Instituto de Investigaciones Jurídicas de la UNAM

proceso electoral y eso es necesario resolverlo de alguna manera puesto que no es pertinente ni para los OPLES ni para el INE negociar con las secretarías de finanzas locales, suficiencias presupuestales para que las elecciones se lleven a cabo, ya que tiene que haber una solución legislativa sobre este punto. También dejo en la mesa un tema que se está discutiendo: el costo de la democracia, el financiamiento que la reforma electoral planteó para los partidos políticos.

Soy un defensor acérrimo del financiamiento público a los partidos políticos; creo en las virtudes del financiamiento público. También coincido con el doctor Astudillo sobre la reforma electoral que le impone al ámbito local un financiamiento a los partidos con la misma fórmula que ya estaba establecida para el ámbito federal; me parece que está generando un costo que no es pertinente al financiamiento de la política. Las cifras del doctor Astudillo revelan que este año, solamente por lo que hace al financiamiento público local a los partidos políticos, hubo un incremento del orden de los 1,500 millones de pesos para financiar la política interna local.

Insisto en el punto, el financiamiento público es una herramienta poderosa y no debe ponerse en entredicho, vale la pena racionalizar los montos que se invierten en la política, ya que todo esto acaba redundando y alimentando lo que hoy tenemos que cuidar; es decir, la pérdida de confianza en las instituciones democráticas, pero sobre todo la pérdida de confianza de la ciudadanía respecto de la política.

En un repensamiento sobre lo que el Estado mexicano invierte en el desarrollo de la política y de la democracia, éste puede abonar en un buen sentido teniendo cuidado de no cerrar la llave del financiamiento para no crearnos problemas peores de los que queremos resolver, ya que hay un margen en el que sensatamente podemos avanzar.

César Astudillo: El consejero presidente del INE ha expresado realmente algo que va al fondo de este conversatorio, es decir, estamos en un momento de balance de reformas que están implementándose por las diversas instituciones y en donde claramente al ponerlas en funcionamiento en la práctica o en el contexto de los procesos electorales se advierte la necesidad de ajustes posteriores, por lo que espero que podamos profundizar en rubros como los siguientes:

1. La imparcialidad de los servidores públicos.

2. La ley de propaganda gubernamental.

3. El procedimiento especial sancionador. 
Esta obra forma parte del acervo de la Biblioteca Jurídica Virtual del Instituto de Investigaciones Jurídicas de la UNAM

4. Las candidaturas independientes.

5. Los tiempos de fiscalización.

6. La flexibilización del formato del modelo de comunicación política.

7. El financiamiento de los OPLES.

Debo decir que en varios de estos temas hay también una doctrina jurisprudencial del Tribunal y valdría la pena que en el eventual ejercicio legislativo se tuviera en cuenta el diálogo entre instituciones electorales como un elemento para tomar determinaciones que vayan en el sentido de fortalecer nuestro andamiaje electoral.

En lo que corresponde a lo electoral, estamos en un contexto diferente en donde el INE y la FEPADE actúan con leyes nuevas, mientras que el Tribunal mantiene una Ley General del Sistema de Medios de Impugnación en materia electoral que data de casi dos décadas. El hecho de tener una legislación del 96, sin actualizar, permite que el ámbito de actuación del Tribunal Electoral coloque en sintonía nuestra legislación.

También se requiere algunos ajustes de carácter formal para armonizar esa ley dentro de la perspectiva de un modelo. Ciertamente, ahora se utilizan leyes generales para tratar de dar una orientación que escape del ámbito federal, pero todavía estamos dejando ámbitos de decisión a los estados, y en ese sentido se debe armonizar lo que regulamos para el ámbito federal; por ejemplo, en los tiempos de fiscalización a los que hacía referencia el doctor Córdova, muchos de éstos están determinados en las legislaciones de los estados, me parece que lo mismo ocurre en materia procesal, hay cuestiones que claramente están reguladas por el ámbito federal pero que necesariamente tienen un espacio en el ámbito local, por lo que si no las homologamos estaremos desfasados y la operación de las instituciones electorales puede verse comprometida.

En ese sentido, me gustaría preguntarle al magistrado Constancio Carrasco Daza, ¿cuál es su opinión sobre la reforma electoral 2014, en relación a su proceso de implementación?

Constancio Carrasco: Coincido con el doctor Lorenzo Córdova en cuanto a la necesaria reforma política de nuestro orden democrático, sobre los déficit y los retos para instrumentar varios de los contenidos del artículo 134 constitucional, que en la sistemática de nuestro bloque de constitucionalidad me hizo recordar un tema que es 
Esta obra forma parte del acervo de la Biblioteca Jurídica Virtual del Instituto de Investigaciones Jurídicas de la UNAM

impostergable en la reforma y que consiste en la regulación de los informes de gestión, de desempeño de los servidores públicos que tienen la obligación de rendir a la ciudadanía informes de labores; esto para mí es un tema que no puede esperar para un debate reflexivo sobre el proceso electoral pasado.

El artículo 6o. de la Constitución federal consagra el derecho humano que tenemos todas las personas en el Estado mexicano para recibir y difundir información de todas las fuentes de cualquier naturaleza, fundamentalmente en materia política tenemos el derecho de recibir información sobre los entes del Estado precisamente para hacer un escrutinio ciudadano del desempeño público, de las políticas públicas, de la gestión, de la rendición de cuentas a la que se refiere el propio artículo 134 de la Constitución federal.

Existe un debate necesario en la reforma política: sobre los informes de gestión de las autoridades que tienen el deber constitucional de hacerlo, si se debe o no regular frente a la Constitución su difusión a través de los medios de comunicación, fundamentalmente televisión y radio.

El artículo 134 constitucional determina expresamente la restricción de toda propaganda gubernamental del Estado mexicano, con las excepciones de nuestro máximo ordenamiento que tienen que ver con funciones o tareas esenciales del Estado que no pueden dejar de difundirse, tales como la posibilidad de que funcionarios públicos, autoridades, legisladores, titulares de los ejecutivos estatales, legisladores federales y locales, y ediles de los ayuntamientos, puedan difundir anualmente sus informes de labores desempeñadas.

Esto se encuentra desde la aprobada codificación electoral en el Cofipe y hace eco en la Ley General de Instituciones y Procedimientos Electorales, permaneciendo incólume el precepto que establece o que regula la facultad de esta clase de servidores públicos en la difusión de sus informes de gestión o desempeño en el periodo concreto; es decir, tiene asidero legal la posibilidad de hacer la difusión de los informes pero el artículo 134 constitucional da un mandato de reflexión absoluto a la difusión.

El artículo 134 no puede leerse de manera aislada, sino en relación con el artículo 60. de la Constitución federal, que establece el derecho de los ciudadanos a recibir toda clase de información, fundamentalmente la que está depositada en los poderes públicos electos, en este caso popularmente. El deber de rendición de cuentas y la propaganda 
Esta obra forma parte del acervo de la Biblioteca Jurídica Virtual del Instituto de Investigaciones Jurídicas de la UNAM

para difundir estos informes es un mecanismo para dar a conocer precisamente la gestión de los servidores públicos.

El artículo 10. constitucional nos exige potenciar los derechos humanos, dentro de ellos el derecho a recibir información por parte de los servidores públicos que difunden sus actividades. La difusión de estos informes de gestión, lo digo de manera muy respetuosa, no ha constituido y no constituye de frente a los procesos electorales concretos una verdadera y genuina rendición de cuentas a la ciudadanía sobre la gestión de los servidores públicos o de los grupos parlamentarios, tratándose del desempeño legislativo.

Está a debate de manera constante en los casos concretos lo que le corresponde resolver al Tribunal Electoral del Poder Judicial de la Federación, específicamente a la Sala Superior, en relación con la propaganda gubernamental, cuando se cuestiona si la difusión de los informes ha constituido o constituye en cada caso concreto una verdadera propaganda que tenga como eje rector o punto esencial que se informe a la ciudadanía de una gestión concreta; es decir, de una agenda de acuerdo a la naturaleza y los objetivos de la función en un periodo determinado.

Este debate es muy difícil de llevarlo a los casos concretos si no tenemos una regulación legal, sin una instrumentación reglamentaria que establezca cuáles son los mínimos que deberá contener la propaganda gubernamental a través de la cual se difundan los informes de gestión de los titulares de poderes ejecutivos estatales, titulares de ayuntamientos, de los congresos estatales y el Congreso federal; es decir, los requerimientos para que a través de estos mínimos que deba contener la propaganda gubernamental se tengan determinadas las posibilidades o lo que se puede informar.

Esto lo ha hecho la jurisprudencia de la Sala Superior del TEPJF guiada por diversas acciones de inconstitucionalidad resueltas por la Suprema Corte de la Nación, que me parece podrían ser base o el piso mínimo a establecerse para una regulación legal, una regulación reglamentaria de los mínimos que debe tener la difusión de propaganda de los informes de gestión.

Creo que todos estamos de acuerdo en que si esta propaganda no informa al ciudadano sobre una gestión concreta, en temas específicos de una agenda natural a la gestión pública de la que se trate al rendir el informe en un periodo determinado, y si tiene otra clase de contenidos u otras finalidades, no estaremos ante una auténtica 
Esta obra forma parte del acervo de la Biblioteca Jurídica Virtual del Instituto de Investigaciones Jurídicas de la UNAM

rendición de informes de gestión que es a la que nos exige el artículo 134 constitucional en la sistemática con el artículo 6o. Es una reflexión que quiero dejar sentada.

Dos temas esenciales, la primera reflexión deriva de que en febrero de 2014 nuestro poder revisor de la Constitución, el Congreso de la Unión, viró de manera importante, refundó en muchos aspectos nuestro sistema político electoral, con una visión diferente del federalismo nacional, una visión contrastada, determinó la rectoría del proceso de organización electoral fundamentalmente del Instituto Nacional Electoral, que crea reglas homogéneas de organización electoral y que concentra un cúmulo importante de atribuciones, estableciendo tres leyes generales: la Ley General de Instituciones y Procedimientos Electorales, la Ley General de Partidos Políticos y la Ley General de Delitos Electorales.

Estas leyes tienen como denominador común que son leyes marco, ya que irradian a todo el sistema electoral, pero quedó pendiente una ley, la ley a través de la cual se enjuician todas las conductas que puedan tener lugar en el sistema nacional electoral por infracciones a estas tres leyes sustantivas.

En el mismo sentido que lo señala el doctor Astudillo, la ley del enjuiciamiento electoral es la misma de 1996, en este tiempo estábamos a cuatro años de la primera alternancia política de nuestro país en la titularidad del Poder Ejecutivo de la nación; hoy esta ley ya no corresponde a la actualidad y difícilmente pasa los estándares mínimos democráticos que debe contemplar una ley de enjuiciamiento.

Actualmente tenemos una nueva Ley de Amparo que comprende todos los actos y autoridades que violan derechos humanos en general; también contamos una ley nacional adjetiva en materia penal creada bajo el reconocimiento y la homogeneidad de los bienes jurídicos que se violentan en una sociedad, ya que son los mismos en todo el territorio nacional, con las propias lógicas que corresponden a la atribución de las legislaturas estatales de configurar tipos penales.

Lo que creo es que el poder revisor de la Constitución determinó que el derecho humano al debido proceso y el derecho humano a la tutela judicial efectiva debían ser los mismos en todo el territorio nacional, puesto que no puede haber un derecho al debido proceso penal en Yucatán y otro derecho de la misma índole en Baja California. Por lo tanto, se reconoció la homogeneidad del derecho al debido proceso como un derecho humano de sede constitucional en nuestro nuevo bloque. 
Esta obra forma parte del acervo de la Biblioteca Jurídica Virtual del Instituto de Investigaciones Jurídicas de la UNAM

La reflexión sería que si tenemos una nueva ley adjetiva en materia penal, ¿habrá un debido proceso en materia electoral? Debe aplicarse la misma lógica constitucional para los procesos electorales, puesto que el debido proceso y la tutela judicial efectiva son las mismas en todas partes. En nuestra ley de enjuiciamiento seguimos reduciendo las posibilidades de acceso a los juicios electorales al interés jurídico, un interés que está muy avanzado en el juicio de amparo y en el reconocimiento a intereses colectivos e intereses legítimos.

Si alguna posibilidad tiene la sociedad en su conjunto o en lo individual de cuestionar los procesos electorales o el resultado de los procesos electorales, es a través de reconocerle su interés legítimo. La suplencia de la queja deficiente es hoy una tarea impostergable que debemos asumir los tribunales, sobre todo los de techo constitucional en los agravios, en los recursos, juicios de revisión constitucional electoral, recurso de reconsideración, las pruebas y su admisión en los medios de impugnación.

Basta revisar el catálogo probatorio y las posibilidades de ofrecer pruebas en todos los juicios electorales para darnos cuenta de lo complejo que es, en los medios de impugnación que son admisibles, encontrar la verdad real con la verdad histórica que subyace en los procesos electorales y en todos estos medios de impugnación que se promueven cuando no se acepta el resultado electoral. Hay que revisar, hacer una ponderación entre la admisión de pruebas que tenemos, la posibilidad de ofrecer pruebas y la capacidad que presentan para poder acreditar o no en los hechos imputados la verdad real histórica de estos hechos.

El artículo 20 constitucional, al referirse sobre el enjuiciamiento penal oral acusatorio, determina que es una de las finalidades del proceso penal la búsqueda de la verdad real de los hechos; yo lo traslado al 41 constitucional y lo dejo como un debate respetuoso.

Una segunda reflexión versa sobre el régimen especial sancionador desde otra arista diferente a la del doctor Lorenzo Córdova. El régimen punitivo, el régimen de sanciones en el procedimiento especial que se tramita contra los verdaderos atentados al modelo de comunicación política en los procesos electorales se encuentra con un énfasis especial al tema de la multa; es decir, el tema de las sanciones pecuniarias a los intervinientes en el proceso electoral, concretamente partidos políticos y candidatos, basta con ver el catálogo de la Ley General de Instituciones y Procedimientos Electorales que hace eco en la multa como la medida más eficaz, ejemplar y disuasiva de esta clase 
Esta obra forma parte del acervo de la Biblioteca Jurídica Virtual del Instituto de Investigaciones Jurídicas de la UNAM

de conducta.

Existe un debate fuerte sobre si las multas que al final se pagan con financiamiento público estatal son verdaderamente eficaces y ejemplares para disuadir esta clase de conductas. Al respecto, tenemos que reflexionar sobre nuestro catálogo, porque de lo contrario no se le está dando respuesta a la sociedad.

Dejo en el debate, muy respetuoso, del Senado la República y en la Comisión de Reforma del Estado, la posibilidad de transitar a la suspensión temporal de la vigencia del registro de los partidos políticos en el propio proceso electoral o con posterioridad al proceso electoral, ponerlos en un punto de equilibrio, no pasar de la cancelación de las multas a la sanción de cancelación del registro; fundamentalmente, esto sucederá cuando se utilicen o se ejerzan recursos de procedencia ilícita en las campañas electorales.

César Astudillo: Vale la pena pensar y advertir que así como hemos puesto atención a dos de los polos fundamentales que sustentan nuestro modelo de organización electoral (el correspondiente a la autoridad nacional electoral y la fiscalía de delitos electorales), es oportuno poner atención a la parte jurisdiccional; aquí hay un desfase procesal que advertí hace unos meses sobre el diseño de los plazos: ¿cuánto se están tardando los tribunales electorales en el ámbito de los estados de la república para resolver los conflictos?, ¿cuánto tiempo se le está dejando al Tribunal Electoral para que haga lo propio? Esto muestra el desfase procesal, la necesidad de ponerle la lupa al diseño de cada uno de los medios de impugnación, porque algo no está bien calibrado cuando vemos que más o menos en promedio el Tribunal Electoral de una entidad de la república tarda 45 días en pronunciarse sobre un determinado medio de impugnación; después, cuando ese medio tiene la posibilidad, como la mayoría lo tiene, de ser revisado inicialmente por la Sala Regional del Tribunal, en promedio tardan en resolverlo 15 días, y después sigue abierta la posibilidad, aun cuando hay condiciones de admisibilidad, la Sala Superior resuelve en un periodo de 2 y 3 días este tipo de recursos, por lo que vemos un desfase. Esto nos debe llevar a las siguientes reflexiones:

1. Los plazos están tan carentes de armonía y no están siendo homologados.

2. Lo anterior produce efectos que no son totalmente saludables para los procesos democráticos.

3. La ley general de enjuiciamiento - coincido con el magistrado Carrasco- podría 
Esta obra forma parte del acervo de la Biblioteca Jurídica Virtual del Instituto de Investigaciones Jurídicas de la UNAM

claramente poner atención en el sistema homologado para evitar las diferencias en los tiempos de resolución de los órganos jurisdiccionales.

Éste es el planteamiento, por lo cual pregunto al doctor Santiago Nieto lo siguiente: ¿cuál es su opinión sobre la reforma electoral 2014 en relación con su proceso de implementación?

Santiago Nieto Castillo: Mi reflexión la dividí en tres apartados:

1. Desde una visión retrospectiva, para comprender si el planteamiento de la reforma ha cumplido con los objetivos planteados.

2. Desde una visión introspectiva, para explicar las experiencias vividas en este año electoral que concluyo con la instalación de la Cámara de Diputados.

3. Desde las reflexiones, para generar una propuesta futura de la reforma.

En el contexto, partimos de que en el dictamen votado por el pleno de la Cámara de Senadores encontramos ciertas líneas argumentativas de todos los partidos políticos relacionadas con la materia de delitos electorales; de esta manera se decía que:

1. Se trataba de una legislación obsoleta que no respondía a la realidad social de la época, la última reforma del Código Penal Federal fue en 1996; por lo tanto, se encontraba rebasado de la realidad social.

2. Se trataba de una ley que criminalizaba la pobreza, se sancionaba por domicilios irregulares (turismo electoral) a las personas de escasos recursos que muchas veces eran movilizadas por los partidos políticos a otros contextos geográficos para que votaran en las elecciones, pero no se perseguía a los instigadores.

3. Sobre el financiamiento y fiscalización de los recursos de los partidos políticos, se pone al debate en primer plano en el financiamiento ilícito, no solamente por recursos de procedencia ilícita sino también por rebasar el tope de gastos de campaña y el topo de aportaciones que pueden ejecutar las personas, así como cualquier violación a las disposiciones en materia de financiamiento. De esta manera, aparte de la responsabilidad administrativa, los legisladores promueven en el ámbito de la legislación penal a una instancia (la FEPADE) que pueda conocer otras conductas delictivas relacionadas con todo el proceso electoral.

¿Qué tenemos como experiencia? Pusimos como fecha de corte el 30 de septiembre; tenemos 1,793 averiguaciones previas, 2,596 actas circunstanciadas y 88 carpetas de 
Esta obra forma parte del acervo de la Biblioteca Jurídica Virtual del Instituto de Investigaciones Jurídicas de la UNAM

investigación, como pruebas un total de 4,477 expedientes. Haciendo un comparativo con las reforma de 1996, la fiscalía recibía anualmente un promedio de 80 denuncias, se consignaban 202 averiguaciones previas en el lapso de 4 años; hoy en día se han incrementado y es necesario abatir ese rezago.

Si tomamos en cuenta el proceso electoral federal pasado, vamos a encontrar que siguen siendo los temas de Registro Federal de Electores (RFE) - la duplicidad de identidad y el domicilio irregular - los delitos más denunciados ante la fiscalía.

En este momento, en cambio, empiezan a despuntar rubros como la compra de votos, la destrucción, alteración, uso y suministro ilegal de materiales y documentos electorales, o el condicionamiento de programas sociales.

Son 2,302 actas circunstanciadas relacionadas con las elecciones del 2015, lo cual significa que nuevamente la FEPADE deja de ser una instancia que tenga como producto central de su actividad la alteración al RFE y se convierte en una instancia que empieza a recibir denuncias relacionadas con el proceso electoral.

Por ejemplo, la compra de votos, el condicionamiento de programas sociales, el recoger credenciales de elector, y el apoyo de subordinados por parte de servidores públicos a campañas electorales son las conductas más denunciadas. Esto ha llevado a la Fiscalía a realizar un proceso de prevención de delitos electorales e incrementar la capacitación previos a la jornada electoral. Los sistemas de atención ciudadana del Fepadetel y Fepadenet en junio y julio se incrementan de manera notable por la jornada electoral en las Ilamadas telefónicas y correos electrónicos, respectivamente.

En este momento tenemos un promedio de 86 consignaciones mensuales, se han librado más de 200 órdenes de aprehensión que están en proceso de cumplimentar. En total tenemos 1,600 órdenes de aprehensión en todo el país a efecto de que sean cumplimentadas para poder avanzar en el proceso penal y llegar a sentencias condenatorias.

¿Cuáles son las reflexiones que nos deja este proceso electoral? Violencia política en contra de las mujeres y en contra de los órganos electorales, la toma de instalaciones del INE, y la obstaculización del adecuado ejercicio de los magistrados, magistradas, consejeros, vocales electorales; todo ello estuvo presente en este proceso electoral sumamente complejo; sin embargo, éste se desarrolló de conformidad con los mandatos normativos y se calificaron las elecciones a través de nuestro sistema constitucional en la 
Esta obra forma parte del acervo de la Biblioteca Jurídica Virtual del Instituto de Investigaciones Jurídicas de la UNAM

materia.

Es necesario considerar dos factores importantes: el número de denuncias en materia de violencia política contra las mujeres se incrementó; no obstante, el aparato legislativo con el que cuenta la FEPADE sigue siendo reducido; tenemos dos tipos penales que permiten conocer de actos de obstaculización al adecuado ejercicio de la función electoral, y en este modelo se han incorporado muchas de las denuncias que se presentan cuando son detenidas, vejadas o atacadas funcionarias electorales; en el caso específico, sobre los actos que provocan temor e intimidación al electorado se han incorporado los actos de violencia política en contra de las mujeres que son atacadas por el simple hecho de ser mujeres, pero sería mucho mejor tener un tipo específico para este tipo de casos.

En 2007 se comenzó a detectar el caso de domicilio irregular y a la fecha se han incrementado de manera considerable pero gracias a los esfuerzos conjuntos con el INE hemos tratado de concientizar a las personas de que no permitan ser utilizadas a cambio de algún trabajo o alguna contraprestación o dadiva, por las implicaciones de la absoluta libertad del sufragio. En Chiapas se presentan este tipo de casos con personas de Guatemala, que acuden con actas falsas, expedidas de manera extemporánea, a solicitar credenciales de elector ante el INE.

Coincido con el doctor Lorenzo Córdova en que la materia electoral hay que pensarla como un continuo histórico de evolución permanente, cada proceso electoral presenta nuevas características que tienen que ser objeto de análisis por parte de los legisladores, autoridades administrativas, de procuración de justicia penal electoral y jurisdiccionales, por lo que planteo los siguientes elementos como una posibilidad de revisión:

1. La creación de un juzgado especializado en materia penal electoral. Existen temas que para los juzgadores penales son prioritarios; al ser los delitos electorales considerados como no graves, la cuestión del plazo para el libramiento de las ordenes de aprehensión ya no se relaciona de manera directa con el proceso electoral, por lo que habría que acortar dichos plazos. En ocasiones concluye el proceso y se siguen integrando las averiguaciones previas, y muchas veces ya no se ve el impacto de la función de la Fiscalía respecto a este tipo de casos. Por ello, tener este tipo de juzgados especializados con juzgadores capacitados con delitos que son muy técnicos en materia electoral podrá permitir tener mejores resultados. 
Esta obra forma parte del acervo de la Biblioteca Jurídica Virtual del Instituto de Investigaciones Jurídicas de la UNAM

2. La especialización. Los jueces penales se vinculan a otros temas relacionados con la delincuencia organizada, contra la salud, secuestro, en tanto que los delitos en materia electoral no tienen el nivel de profundidad que deberían tener.

3. Acortar los plazos para librar las órdenes de aprehensión. Existen una diversidad de criterios para interpretar las normas jurídicas, para librar una orden de aprehensión entre los juzgadores; hay quienes solicitan 3 elementos probatorios del expediente, otros piden 22 elementos probatorios para librar una orden de aprehensión, pero si se cuenta con la misma conducta delictiva y el mismo nivel de interpretación por parte de la Suprema Corte, no habría distinción en el carácter probatorio.

El hecho de que tenga el juzgador dos días hábiles para radicar y diez días hábiles para decidir si se libra o no la orden de aprehensión es mucho tiempo, impacta de manera directa en la eficacia de la función de la justicia penal electoral. En consecuencia, si estamos hablando de campañas electorales que duran 30, 45 ó 60 días, en lo que se libra la orden de aprehensión se pierde entre 17 y 19 días; en un proceso electoral esto se convierte en un mundo de tiempo y se corre el riesgo de que la Fiscalía llegue tarde a los procesos.

4. Medidas cautelares en caso de violencia política. Hay que reflexionar sobre un sistema de atención temprana instrumentado por parte de la FEPADE, a través de telefonía y correo electrónico, para recibir y canalizar las denuncias por violencia política contra las mujeres; pero sería mucho más importante avanzar en un sistema de atención temprana que permita proteger los derechos político-electorales de las candidatas y funcionarias electorales.

5. Protección interna entre los partidos políticos. En donde no hay una injerencia directa por parte de la FEPADE, el tema central tendrá que ver con la transición del sistema penal acusatorio: el nuevo modelo a partir de la intermediación, de la economía procesal, del principio contradictorio y de la oralidad, lo que obliga a las autoridades procuradoras de justicia penal electoral a plantear de forma directa nuestros argumentos.

Tuvimos nuestra primera audiencia en Yucatán, la que se vinculó al proceso y creemos que vamos a tener buen resultado en un caso relacionado con las elecciones del 2015; sin embargo, éste no es el proceso más importante que tiene la materia, ya que se nos presentan criterios de oportunidad y la posibilidad de acuerdos restauratorios en 
Esta obra forma parte del acervo de la Biblioteca Jurídica Virtual del Instituto de Investigaciones Jurídicas de la UNAM

esta materia.

Hasta antes de la reforma de 2014, la materia penal electoral no se centraba en las víctimas de la comisión de delitos electorales: el objetivo era la sociedad en su conjunto. Hoy en día estamos hablando de denuncias por parte de personas físicas que son víctimas de la comisión de un delito electoral, por lo que habrá que empezar desde una dogmática de derecho electoral a reformular los replanteamientos institucionales para dar mejores resultados a la ciudadanía.

César Astudillo: Déjenme exponer seis elementos sobre la perspectiva de los tres titulares de las instituciones electorales del país a nivel nacional y lo que debemos afrontar en el futuro inmediato.

1. Está un escenario de omisiones legislativas. Es prudente puntualizar la oportunidad de que el legislador tome la iniciativa para colmar algunos ámbitos de la organización electoral que se encuentran descubiertos. Hay omisiones totales, es decir, la inexistencia de leyes completas, como la Ley General de Propaganda Gubernamental, Reglamentaria de los Artículos 6o. y 134 de la Constitución Política de los Estados Unidos Mexicanos, y también omisiones parciales que requieren adecuación; por ejemplo, el tema de un nuevo caudal probatorio en al ámbito procesal y la parte de la redefinición de las medidas cautelares a las que hacía referencia el doctor Lorenzo Córdova.

2. La armonización normativa. Se refiere a la necesidad de empatar toda nuestra legislación con otras normas que ya existen dentro del ordenamiento jurídico; pongo el énfasis en lo comentado por el magistrado Carrasco: si la Ley de Amparo ya tutela un interés más amplio, es necesario armonizar la Ley General de Medios de Impugnación en Materia Electoral para avanzar hacia un interés legítimo.

3. La especificación normativa. Contamos con una regulación al respecto, pero la experiencia reciente ha puesto la necesidad de que el legislador sea todavía más puntual. Ejemplo, tenemos a las candidaturas independientes que están reguladas, tienen un asidero constitucional, un referente en la legislación pero claramente existen un conjunto de elementos que están sujetos a la potestad de cada uno de los estados. En este ámbito hay ocasiones en las que se legisla de manera razonable y otras en que no; por eso, el Tribunal ha señalado que existen regulaciones del legislador que son contrarias al orden constitucional. 
Esta obra forma parte del acervo de la Biblioteca Jurídica Virtual del Instituto de Investigaciones Jurídicas de la UNAM

4. La homologación normativa. Es necesario uniformar procesos, procedimientos y plazos; por ejemplo, tenemos en la fiscalización —-como hacía referencia el doctor Córdova - la necesidad de articular el plazo establecido en la ley con la doctrina jurisprudencial y los plazos para resolver los medios de impugnación en la materia.

5. Definición normativa o definición política. La reforma quedó incompleta, porque no se garantizó la autonomía de los organismos públicos electorales al dejar descubierta la parte económica, al ser este rubro un referente indispensable para garantizar la independencia respecto de quienes tienen que aprobar los presupuestos de los órganos electorales.

6. La reforma de la reforma. En la dinámica de los procesos electorales, la experiencia nos enseña que las reformas necesitan ser retocadas, y con ello, lograr el ajuste en ámbitos muy sensibles del sistema democrático, como los ya referidos en esta mesa: procesos de fiscalización, procesos de pruebas, proceso especial sancionador y el modelo de comunicación política.

Creo que éstos serían seis rubros en los que podrá articularse lo que aquí se ha dicho.

Aprovechando la presencia de los tres titulares, les hago cuatro preguntas generales en perspectiva y les pido una reflexión, que sería conclusiva, porque me parece que pasan estas preguntas por el prisma de las tres grandes instituciones electorales que articulan nuestro modelo de organización electoral.

Las preguntas son las siguientes:

1. ¿Hay una política institucional de parte de las tres instituciones en materia electoral para fortalecer los derechos políticos de grupos vulnerables?

2. ¿Hay políticas institucionales conjuntas sobre paridad y las condiciones de la competencia política?

3. ¿Hay una política institucional para favorecer a los OPLES en cuanto a su independencia y autonomía?

4. ¿Necesitamos más regulación o desregulación en nuestro sistema electoral?

Lorenzo Córdova: Considero que muchos de los problemas en materia electoral no se van a resolver desde este ámbito, no hay que sobrecargar las expectativas en las autoridades electorales. Tenemos un déficit de cultura democrática o de cultura cívica para afrontar responsablemente como órganos del Estado. 
Esta obra forma parte del acervo de la Biblioteca Jurídica Virtual del Instituto de Investigaciones Jurídicas de la UNAM

Respecto a la primera pregunta, no es que haya una política, ha sido tan vertiginosa la instrumentación de la reforma que no nos ha dado tiempo de pensar a priori en una política en esta materia, pero en la vía de los hechos hoy sí podemos hablar de una política en este sentido, concretamente en el tema de la participación política de las mujeres.

El Tribunal Electoral en 2012 había planteado, por ejemplo, con el cumplimiento de las cuotas en las candidaturas, la ruta que luego el legislador constituyente retoma y ensancha al establecer el tema de la paridad. El Tribunal Electoral ahora contempla la paridad en las candidaturas a cargos legislativos federales y locales, y ha marcado la ruta sobre la cual hay que avanzar; por ejemplo, al plantear el tema de la paridad horizontal y vertical en el ámbito municipal, y esto ha tenido un acompañamiento muy claro de los órganos electorales.

Insisto no es una política pensada, pero sí por la vía de los hechos hay un consenso que en breve se llevará a la aprobación del Consejo General hacía finales de este mes. El punto consiste en retomar la jurisprudencia del Tribunal, la cual no fue respetada en Chiapas a pesar de que tiene el carácter de vinculante; ello ha implicado que hoy estemos conociendo de procedimientos en contra de quienes integran ese órgano electoral; por la vía de la atracción y por la vía de criterios generales que nosotros podemos emitir, vamos a reforzar este punto, no porque sea indispensable, ya que como dije- la jurisprudencia del Tribunal es vinculante, sino porque el INE es quien nombra y eventualmente remueve a los consejeros electorales de los órganos electorales estatales.

Más vale que nosotros mismos nos sumemos a esa política y mandemos en ejercicio de nuestras atribuciones constitucionales; es decir, atraer para fijar criterios vinculantes y para que a nadie le quede duda que la ruta que ha fijado el Tribunal es la ruta que nosotros mismos estaremos vigilando que se siga. Así que por la vía de una política propiamente dicha no nos hemos sentado para saber por dónde vamos a caminar y para definir con pleno alcance una línea común, pero sobre la vía de la interpretación si se está dando una política en este sentido.

En materia de discapacidad el INE ha tenido una política muy clara: se adoptaron el uso de plantillas en braille; la colocación de mamparas móviles, que permiten a las personas que acuden a las casillas en sillas de ruedas, garantizarles la secrecía de su voto; 
Esta obra forma parte del acervo de la Biblioteca Jurídica Virtual del Instituto de Investigaciones Jurídicas de la UNAM

en los procedimientos del registro federal de electores, la posibilidad de atender o credencializar en el domicilio cuando haya una justificación que lo avale; y la accesibilidad de nuestras instalaciones, que están pensadas para personas con discapacidad.

En cuanto al artículo 38 constitucional, que establece la suspensión de los derechos fundamentales, han de maximizarse los derechos políticos como lo plantea el artículo 10. constitucional, pensando en la posibilidad de otorgar los derechos políticos de votar y ser votado a las personas que están purgando una pena corporal: en muchos países se instalan casillas en los centros de reclusión para que se ejerza este derecho. Habrá que discutir el tema.

En relación con las condiciones ambientales en el tema de la paridad, el Tribunal Electoral ha sido sendero en este sentido y nosotros hemos ido con este tema de la paridad a tope, incluyéndolo en distritos ganadores, un asunto complicado que la ley ya establece. Nosotros obligamos a los partidos políticos a contemplar esos estatutos, que en las convocatorias para cargos de elección popular determinaran, lo que entenderían por distritos ganadores y cómo procederían para cumplir con esta obligación legal. En términos generales aunque los partidos recurrieron a distintos mecanismos, creo que eso funcionó y bastante bien.

Hay una política institucional para fortalecer la autonomía de los OPLES; el papel del INE ha sido el de un órgano rector, de coordinación y seguimiento del empaque del sistema electoral nacional, y esto pasa por las experiencias recientes como un seguimiento mucho más puntual, más cercano a los OPLES en cuanto a su trabajo y funcionamiento. Hay que decir que existen algunos organismos en los que no acaba de solidificar el trabajo colegiado, el cual es un trabajo complejo que no pasa meramente por mayoritear a los demás, sino para construir consensos, o bien que ha venido enfrentándose con problemas presupuestales que son delicados.

Hoy el INE tiene un déficit de 40 millones de pesos que algunos OPLES tienen que transferir a éste en virtud de que el costo de la casilla única fue a mitades, hay OPLES que enfrentan situaciones presupuestales graves, por lo que diría que no hay "manga ancha" a los OPLES: existen abusos que no podemos permitir y menos en los tiempos que pasan en términos presupuestales. De cualquier manera, por la vía presupuestal no podemos vulnerar la autonomía de los OPLES. 
Esta obra forma parte del acervo de la Biblioteca Jurídica Virtual del Instituto de Investigaciones Jurídicas de la UNAM

En este sentido, hemos definido, junto con el magistrado Carrasco, hace unas semanas cuáles son las reglas que tendrán que seguir los OPLES en el nombramiento de sus órganos desconcentrados, para evitar cualquier injerencia indebida de actores políticos para poner mayorías definidas blindadas al interior de los OPLES que rompen el trabajo colegiado.

Previmos que además de las legislaciones locales que regulan lo contrario, los cargos directivos de los OPLES tienen que ser propios de los consejos generales, porque hay algunas legislaciones en que el Poder Legislativo designa al secretario ejecutivo o a los directores ejecutivos; los nombramientos legislativos son nombramientos políticos, por lo que no podemos permitir que en el caso de los órganos electorales haya nombramientos de tipo político. El INE intervendrá a fondo en el acompañamiento, será crítico que genere contextos de exigencia del trabajo de los OPLES para acompañarlos en el blindaje y fortalecimiento de su autonomía.

Por último, yo diría que no necesitamos más regulación, existen temas en los que se debe pensar su continuidad. ¿Tenemos que seguir votando en papel seguridad? La ley dice que sí, habría que discutirlo. En términos generales apostemos a una desregulación de todos aquellos temas en que no tenemos un problema de fondo, cuidando mucho de no abrir o no reabrir esos conflictos que ya están superados; pero se encuentran otros temas que ameritan una regulación más clara y que no conviene que hoy estén sujetos a los criterios interpretativos del Tribunal y del INE, porque donde tenemos que interpretar hay algún grado de discrecionalidad. Entre menor discrecionalidad tengamos los órganos electorales en la toma de decisiones, es mejor para todos.

En cuanto al tema de las candidaturas independientes, apostaría a que no haya restricciones a la libertad de expresión en las contiendas electorales, en la propaganda electoral. Los partidos ya decidirán si apuestan por campañas de contraste, si les redunda en beneficio electoral y en credibilidad pública, por lo que no es pertinente que la autoridad electoral establezca lo que los partidos pueden o no decir.

César Astudillo: magistrado Constancio Carrasco, ¿Cuál es su opinión al respecto?

Constancio Carrasco: ¿Cómo ensanchar los derechos políticos-electorales? En el Tribunal Electoral del Poder Judicial de la Federación estamos proponiendo la creación de la defensoría pública en materia de derechos políticos de las comunidades y personas indígenas en nuestro orden jurídico nacional. Lo ha expresado muy bien el doctor 
Esta obra forma parte del acervo de la Biblioteca Jurídica Virtual del Instituto de Investigaciones Jurídicas de la UNAM

Santiago Nieto: las mujeres han sido muy vulnerables frente a la comisión de delitos en este proceso electoral; existe una historia de vulnerabilidad de las mujeres frente a los procesos electorales y su utilización muchas veces para la comisión de delitos en materia electoral. Esto justifica la creación de la defensoría pública que responda a las necesidades políticas mínimas de las mujeres indígenas en México; estaremos haciendo mucho por pasar a los hechos de una tutela judicial que les permita mayor inclusión.

Coincido con el doctor Lorenzo Córdova en el ejercicio de los derechos políticos de quienes están privados de su libertad, incluyendo la sentencia de condena, un tema que tendremos que abrir y discutir.

¿Necesitamos más reformas? El tema tiene que ver con cultura de la legalidad; en cualquier democracia deben estar presentes los temas de la creación y la confección legislativa, la cultura de la legalidad y la madurez política al seno de nuestra sociedad. Partidos políticos, candidatos, pero sobre todo de las autoridades, tenemos que debatir cómo vamos en cultura de la legalidad.

Los procesos electorales no están para resolver los problemas nacionales, que tanto nos duelen y aquejan, están para resolver el acceso de los candidatos a los cargos públicos de manera democrática, a los que les corresponde resolver con eficacia es a los electos popularmente por el pueblo, que sean ejemplares para que a partir de ahí desempeñen los cargos a la altura de lo que hoy la sociedad nos demanda.

César Astudillo: Estos mismos cuestionamientos le pregunto al doctor Santiago Nieto: ¿qué opina sobre estos temas?

Santiago Nieto: El Tribunal Electoral y el INE ya habían desarrollado políticas institucionales a favor de grupos vulnerables y era muy importante que la FEPADE no se quedara atrás de este proceso. Dentro de las líneas discursivas de los acuerdos generados en el INE, de las sentencias de la Sala Superior y las salas regionales del Tribunal Electoral, se puede encontrar esa vertiente argumentativa a favor de los derechos de las mujeres indígenas, discapacitados, y en eso hemos avanzado mucho y comparto la idea en este sentido.

Me parece muy interesante el tema del voto de las personas que se encuentran sujetas a un proceso penal, ya que hay personas que a pesar de que su delito no sea grave siguen privados de su libertad por no tener el dinero suficiente para pagar una libertad caucional; en este aspecto toma mucho sentido lo expresado por el magistrado 
Esta obra forma parte del acervo de la Biblioteca Jurídica Virtual del Instituto de Investigaciones Jurídicas de la UNAM

Carrasco en lo referente a defender a grupos vulnerables en el ámbito de los derechos político-electorales. Además, la propia Convención Americana en el artículo 23 señala que no se restringen los derechos políticos, sino sólo con sentencia ejecutoriada, y me parece que la restricción del auto de formal prisión sí puede ser excesiva.

En cuanto a la autonomía, la Ley General en Materia de Delitos Electorales establece en su artículo 24 la obligación de que la FEPADE coordine las fiscalías electorales locales. En este momento es un paso importante que dar porque existe una enorme disparidad institucional; así, tenemos fiscalías que cuentan con un Ministerio Público especializado y, en contraste, fiscalías que durante el proceso electoral autorizan a un Ministerio Público para que pueda desarrollar la función electoral; también se habilita a la agencia a efecto de que reciban las denuncias por delitos electorales, pero esto no significa que hay un conocimiento especializado. Por ello, habría que abrir paso a la apertura de fiscalías especializadas en materia de delitos electorales en las entidades federativas que puedan asumir sus funciones y organizar este proceso de procuración de justicia penal electoral de la mejor forma posible.

Finalmente, hablamos de la desregulación; en ese sentido, tenemos un modelo republicano en oposición al modelo liberal que se puede encontrar en los Estados Unidos donde tienen libertad absoluta y pocas restricciones; el modelo mexicano es más pensado en los controles, es de alguna forma nuestra tradición europea heredada del positivismo clásico, estamos planteando que la ley nos van a dar todas las soluciones; sin embargo, la parte central es ¿qué del sistema es eficaz para que se regule? y ¿qué del sistema es eficaz para que se desregule? En materia de medios de comunicación por supuesto, aunque también en materia de tipos penales, acabamos de consignar y libraron orden de aprehensión en donde personas habían publicado resultados electorales durante la época de veda en jornada electoral. La pregunta es ¿tendría que ser éste un delito electoral? o ¿bastaría con que fuera una sanción de naturaleza administrativa? La ley de delitos electorales no es una ley muy amplia, son 26 artículos; considero que hay cosas que se pueden perfeccionar, pero creo que lo más importante es transitar a una manera de procuración eficaz, transparente, y en la cual se protejan los derechos fundamentales de las partes, y con ello, ayudar a la consolidación de la democracia mexicana.

César Astudillo: Muchas gracias a nuestros tres personajes entrevistados, a los tres titulares de nuestras instituciones electorales. 
Esta obra forma parte del acervo de la Biblioteca Jurídica Virtual del Instituto de Investigaciones Jurídicas de la UNAM www.juridicas.unam.mx https://biblio.juridicas.unam.mx/bjv

https://revistas.juridicas.unam.mx/

Dol: http://dx.doi.org/10.22201/iij.24487910e.2015.7.10093

Me parece que de aquí emanan reflexiones interesantes, muy puntuales sobre la orientación de una eventual reforma electoral en el futuro no lejano.

DR (C) 2018. Instituto de Investigaciones Jurídicas, UNAM, https://revistas.juridicas.unam.mx/index.php/derecho-electoral/issue/archive 